\title{
A Hybrid Controller for Position Control of a Pneumatic Actuator under Variable Loading Conditions
}

\author{
Sukhdeep Singh Dhami \\ Mechanical Engineering Department, National Institute of Technical Teachers Training and Research, Chandigarh, India
}

\begin{abstract}
Pneumatic actuators are preferred for low to medium power requirements due to their desirable features like large power to weight ratio, low cost and safe working medium. Position control of pneumatic actuators is however difficult due to inherent nonlinearity-contributing factors. Therefore, position control of pneumatic actuators have been found to be a challenging task using fixed gain controllers. Sliding mode control can be used to overcome this difficulty. Further, the nonlinear response of pneumatic actuators under variable loading conditions makes it a fit case for using heuristic control based on the knowledge of the system behaviour. This may be done by using fuzzy logic based control approach. In the present work, a hybrid controller was synthesized using fuzzy logic control and sliding mode control for position control of a pneumatic actuation system. The quantitative results emphasized that hybrid FLC-SMC controller exhibited effective position control for pneumatic actuation system as fuzzy logic control was effective for combinations of lower payloads and smaller piston displacements, whereas sliding mode controller was effective for combinations of higher payloads and larger piston displacements.
\end{abstract}

\section{Introduction}

Pneumatic actuators are preferred for low to medium power requirements due to their desirable features like large power to weight ratio, low cost and safe working medium. Position control of pneumatic actuators is however difficult as compared to hydraulic and electromechanical systems due to nonlinearitycontributing factors like air compressibility, airflow through orifice and friction etc. A multitude of control techniques have been reported in literature for minimizing the positional error in pneumatic servo systems. Such techniques include PID control, modified PID control, fuzzy logic based control and sliding mode control etc.

\section{Literature Review}

Nguyen et al. [1] proposed a sliding mode approach for positioning a $2 \mathrm{~kg}$ mass using a double-acting pneumatic motion control system. The tuning of the controller parameter was done experimentally. The results for 20 $\mathrm{mm}$ amplitude and $0.5 \mathrm{~Hz}$ frequency sinusoidal and square wave trajectories, exhibited a tracking error of \pm 2 $\mathrm{mm}$ range. Bone and Ning [2] developed two sliding mode controllers, one based on linearized plant model, labeled Sliding Mode Control Linear (SMCL) and the other based on nonlinear plant model, labeled Sliding Mode Control Nonlinear (SMCN), for positioning $1.9 \mathrm{~kg}$, $5.8 \mathrm{~kg}$ and $10.8 \mathrm{~kg}$ payloads. The controller parameters were tuned manually for the nominal load of $5.8 \mathrm{~kg}$, in both cases. The results showed that the SMCL exhibited superior control of $10.8 \mathrm{~kg}$ payload and inferior control of $1.9 \mathrm{~kg}$ payload, whereas the opposite was true for SMCN. Taghizadeh et al. [3] designed and implemented a multimodel controller for position control of a variably loaded pneumatic actuator. A multimodel controller was designed for a number of constant loads and corresponding to each load, a linear model was identified and a PD-controller was tuned for the system. A switching algorithm was applied which determined the best model and selected the corresponding controller in any load condition. Experimental results indicated good performances of the multimodel controller under variable load conditions. Taleb et al. [4] presented a new secondorder sliding-mode algorithm for position control of a pneumatic actuator. Due to the dynamic adaptation of the gains, the controller design did not require complete information on the bounds of uncertainties and perturbations. It automatically decreased the gains and oscillations due to a too large discontinuous-control magnitude. Salim et al. [5] proposed a self-regulating nonlinear PID controller for a pneumatic positioning system for a variably loaded pneumatic actuator. Simulation and experimental tests conducted with different types of inputs showed improved transient and steady state response vis-à-vis previously reported nonlinear PID controllers. 


\section{Objective}

The objective of present work is to synthesize a hybrid controller, using fuzzy logic control and sliding mode control, for position control of a pneumatic actuation system shown in Figure 1. The nomenclature and values of system parameters are given in the Appendix.

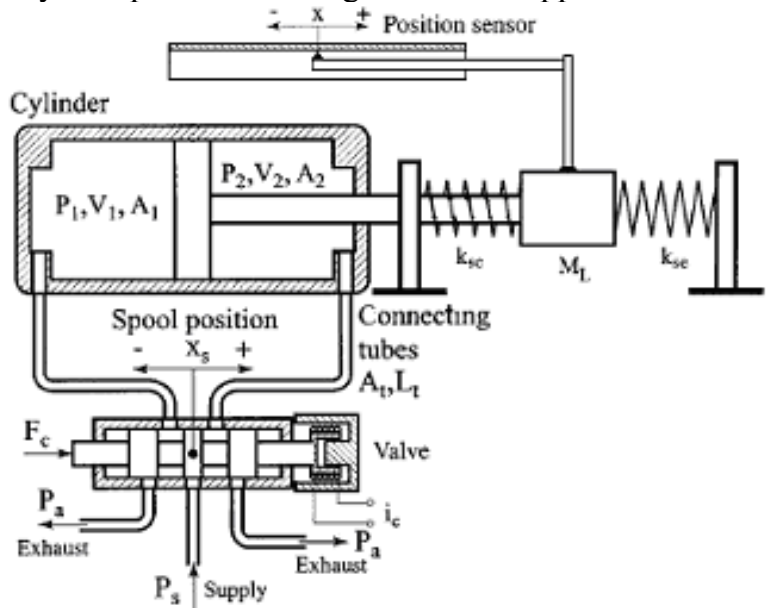

Figure 1. Schematics of pneumatic servo system [6]

The variable loading conditions, in terms of combinations of piston payload and desired piston displacement, considered in the present work are shown in Table 1.

Table 1: Payload $\left(\mathrm{M}_{\mathrm{L}}\right)$ and desired piston displacement $\left(\mathrm{x}_{\mathrm{d}}\right)$ combinations

\begin{tabular}{|c|c|c|c|}
\hline $\begin{array}{c}0.1 \mathrm{~kg}, \\
\pm 30 \mathrm{~mm}\end{array}$ & $\begin{array}{c}0.4 \mathrm{~kg}, \\
\pm 30 \mathrm{~mm}\end{array}$ & $\begin{array}{c}0.7 \mathrm{~kg}, \\
\pm 30 \mathrm{~mm}\end{array}$ & $\begin{array}{c}1.0 \mathrm{~kg}, \\
\pm 30 \mathrm{~mm}\end{array}$ \\
\hline $\begin{array}{c}0.1 \mathrm{~kg}, \\
\pm 20 \mathrm{~mm}\end{array}$ & $\begin{array}{c}0.4 \mathrm{~kg}, \\
\pm 20 \mathrm{~mm}\end{array}$ & $\begin{array}{c}0.7 \mathrm{~kg}, \\
\pm 20 \mathrm{~mm}\end{array}$ & $\begin{array}{c}1.0 \mathrm{~kg}, \\
\pm 20 \mathrm{~mm}\end{array}$ \\
\hline $\begin{array}{c}0.1 \mathrm{~kg}, \\
\pm 10 \mathrm{~mm}\end{array}$ & $\begin{array}{c}0.4 \mathrm{~kg}, \\
\pm 10 \mathrm{~mm}\end{array}$ & $\begin{array}{c}0.7 \mathrm{~kg}, \\
\pm 10 \mathrm{~mm}\end{array}$ & $\begin{array}{c}1.0 \mathrm{~kg}, \\
\pm 10 \mathrm{~mm}\end{array}$ \\
\hline
\end{tabular}

\section{Methodology}

MATLAB and Simulink application software were used for modeling and simulating the pneumatic actuation system as well as for designing fuzzy logic and sliding mode controllers for the system. Modeling and simulation of the pneumatic actuation system was done using its mathematical and virtual models developed by Dhami et al. [7]

\subsection{Modeling, Simulation and Control of Pneumatic Servo System}

The mathematical model of the pneumatic actuation system consists of dynamics of control valve, air flow dynamics through control valve ports and connecting tubes, pressure dynamics in cylinder chambers and dynamics of piston and load. Virtual model of the pneumatic actuation system was developed in MATLAB/Simulink and used for simulating the system.
For designing Fuzzy Logic Controller for the system, the positional error, rate of change of error and the applied external load were taken as input variables and the control signal as the output variable. Trapezoidal membership functions were used for defining the fuzzy sets of input parameters and linear membership functions for output variable. A Sugeno type fuzzy logic controller was designed using the input and output data of dynamic response of pneumatic actuation system obtained by simulations.

The surface of sliding mode controller for pneumatic servo system is given by

$$
S=\left(\ddot{x}-\ddot{x}_{d}\right)+2 \lambda\left(\dot{x}-\dot{x}_{d}\right)+\lambda^{2}\left(x-x_{d}\right)
$$

where $\lambda$ is a strictly positive constant. The dynamics in sliding mode are given by

$$
\dot{S}=0
$$

Solving equation (2), the equivalent control signal ' $u_{\mathrm{eq}}$ ' was obtained and combined with a saturation term for satisfying sliding mode condition. The resulting control action ' $u$ ' was given by:

$$
u=u_{e q}-k \operatorname{sat}\left(\frac{S}{\phi}\right)
$$

where 'sat' is the saturation function defined as

$$
\left.\begin{array}{l}
\operatorname{sat}(y)=-1, \text { if } y<-1 \\
\operatorname{sat}(y)=y, \text { if }-1 \leq y \leq 1 \\
\operatorname{sat}(y)=+1 . \text { if } y>1
\end{array}\right\}
$$

The controller parameters $-\lambda, \mathrm{k}$ and $\phi$ were manually tuned. It was found that satisfactory positional response was not possible for different combinations of payloads and linear displacements, for a single set of controller parameter values. The most dominant parameter ' $\lambda$ ' was varied and tuned for different operative conditions. The tuned values of $\mathrm{k}$ and $\phi$ were found to be 10 and 100 respectively. Values of $\lambda$ tuned for different operative conditions are given in Table 2.

Table 2. Values of $\lambda$ for different payload and piston displacement combinations

\begin{tabular}{|c|c|c|c|c|}
\hline load $\rightarrow$ & $0.1 \mathrm{~kg}$ & $0.4 \mathrm{~kg}$ & $0.7 \mathrm{~kg}$ & $1.0 \mathrm{~kg}$ \\
\cline { 1 - 4 } displacement $\downarrow$ & & & & \\
\hline$-30 \mathrm{~mm}$ & 220 & 210 & 200 & 170 \\
\hline$-20 \mathrm{~mm}$ & 220 & 180 & 170 & 150 \\
\hline$-10 \mathrm{~mm}$ & 210 & 170 & 150 & 120 \\
\hline$+10 \mathrm{~mm}$ & 210 & 110 & 100 & 90 \\
\hline$+20 \mathrm{~mm}$ & 210 & 160 & 130 & 110 \\
\hline$+30 \mathrm{~mm}$ & 200 & 180 & 170 & 150 \\
\hline
\end{tabular}

\subsection{Performance evaluation of fuzzy logic and sliding mode controllers}

The positional response of the pneumatic actuation system was simulated for different operative conditions using FLC and SMC independently. The transient and steady state positional responses of pneumatic actuation system were quantified in terms of rise time, percent overshoot, settling time, steady state error and integral of 
absolute error. The first four parameters were computed using Control System Toolbox of MATLAB. Integral of Absolute Error (IAE) is a quantitative measure of the performance of dynamic systems and it is particularly useful for computer simulation studies [8]. IAE is mathematically defined as

$$
I A E=\int_{0}^{T}|e(t)| d t
$$

where $\quad e(t)$ is the instantaneous error

$\mathrm{T}$ is the simulation time duration

The IAE performance index gives a high value for both excessively overdamped and underdamped systems. A smaller value of IAE signifies improved transient response.

Table 3 shows the comparative values of transient and steady state parameters obtained using fuzzy logic control (FLC) and sliding mode control (SMC) independently. The units of Payload, Reference Position, Rise Time, Overshoot, Settling Time, Steady State Error and IAE are $\mathrm{kg}, \mathrm{mm}$, second, percentage, second, $\mathrm{mm}$ and $\mathrm{mm}$ respectively. Further, the settling time was computed using $\pm 5 \%$ criterion. For steady state error more than $\pm 5 \%$, the settling time is shown as $\mathrm{NaN}$.

The following inferences were drawn from positional response and data in Table 2:

- Rise time was smaller for sliding mode control for all payload-displacement conditions.

- Overshoot was lower for sliding mode control for payloads of $0.4 \mathrm{~kg}, 0.7 \mathrm{~kg}$ and $1.0 \mathrm{~kg}$ but it was higher for payload of $0.1 \mathrm{~kg}$.
- Settling time was less for sliding mode control for $1.0 \mathrm{~kg}$ payload and $\pm 30 \mathrm{~mm}$ piston displacement, but it was higher for most of other payloaddisplacement conditions.

- Steady state error was less for sliding mode control in case of higher payload and higher piston displacement combinations.

- IAE was remarkably lower for sliding mode control in case of combinations of $0.7 \mathrm{~kg}$ and $1.0 \mathrm{~kg}$ payloads and $\pm 20 \mathrm{~mm}$ and $\pm 30 \mathrm{~mm}$ piston displacements.

- It was observed from positional response that Sliding Mode Control resulted in excessive piston dithering at steady state for lower payloads $(0.1 \mathrm{~kg}$ and $0.4 \mathrm{~kg})$ and all reference positions. For higher payloads and smaller reference positions, marginal dithering of piston was observed at steady state.

\subsection{Synthesis of Hybrid Controller}

Based on the quantitative analysis of transient and steady state piston positional response, a hybrid-control matrix was formulated for position control of pneumatic actuation system, Table 4 . The matrix represents hybrid control approach as it employs both Fuzzy Control and Sliding Mode Control approaches for relevant combinations of piston payload and piston position.

Simulink model of the synthesized hybrid model is shown in Figure 2. The exploded view of the hybrid controller is shown in Figure 3, in which the 'Control Signal Selection Criteria' block incorporates Table 3.

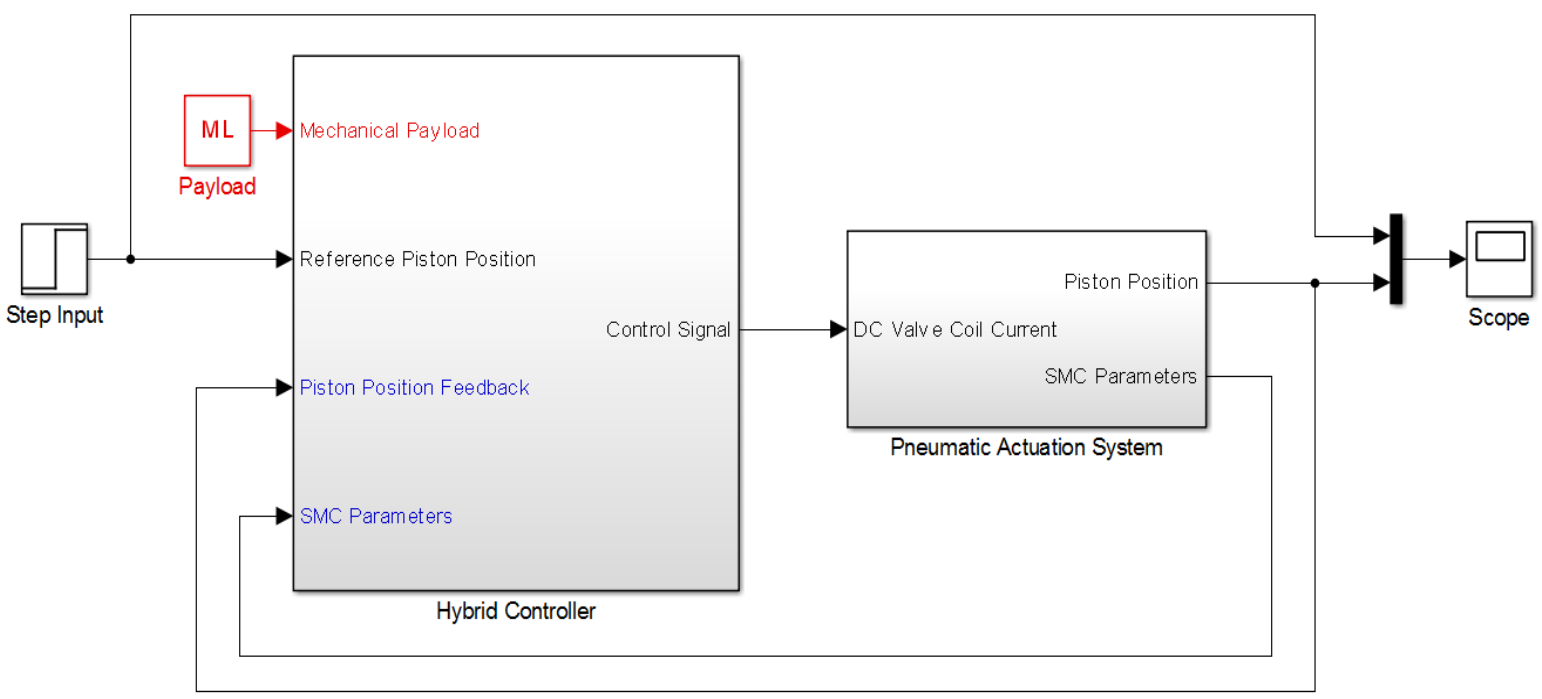

Figure 2. Simulink model of synthesized hybrid controller

\section{Results and discussions}

The positional response of the pneumatic actuation system using hybrid controller for different payloaddisplacement combinations is presented in Figure 4. Hybrid controller selects sliding mode control for payload-displacement combinations of $(0.7 \mathrm{~kg}, \pm 30 \mathrm{~mm})$, $(1.0 \mathrm{~kg}, \pm 20 \mathrm{~mm})$ and $(1.0 \mathrm{~kg}, \pm 30 \mathrm{~mm})$, whereas for other combinations fuzzy control was employed.

For $0.1 \mathrm{~kg}$ payload, fuzzy control results in very good transient as well as steady state response. For $0.4 \mathrm{~kg}$ payload, fuzzy control results in slightly increased 
transient oscillations, but both transient and steady state response is satisfactory as indicated by IAE, settling time, steady state error. For payload-displacement combinations of $(0.7 \mathrm{~kg}, \pm 20 \mathrm{~mm}),(0.7 \mathrm{~kg}, \pm 10 \mathrm{~mm})$ and $(1.0 \mathrm{~kg}, \pm 10 \mathrm{~mm})$, fuzzy control results in high overshoot, but it is preferred as settling time and steady state error are less than those in case of sliding mode control. For the remaining combinations of payload and piston displacement, sliding mode control resulted in piston dithering, but it was quite small and the transient as well as steady state responses were very good as indicated by performance parameters for these combinations.

The steady state positional error and integral of absolute error obtained with hybrid control of pneumatic actuation system under different operative conditions are shown in Figure 5. The maximum steady state error was $1.66 \mathrm{~mm}(5.5 \%)$ for a desired piston position of $30 \mathrm{~mm}$ with $0.1 \mathrm{~kg}$ payload. The average steady state error for lower payloads $(0.1 \mathrm{~kg}$ and $0.4 \mathrm{~kg})$ is almost same and higher than that obtained for other two payloads. The maximum IAE was 7.25 for a desired piston position of $30 \mathrm{~mm}$ with $0.4 \mathrm{~kg}$ payload. The average IAE of 6.74 for payloads of $0.1 \mathrm{~kg}, 0.4 \mathrm{~kg}$ and $0.7 \mathrm{~kg}$ was more than double for that obtained for $1.0 \mathrm{~kg}$ payload. Higher IAE for payloads of $0.1 \mathrm{~kg}$ and $0.4 \mathrm{~kg}$ was due to higher steady state positional error at these payloads for all reference positions. Higher IAE for $0.7 \mathrm{~kg}$ payload was due to increased transient oscillations for $\pm 20 \mathrm{~mm}$ reference piston positions.

Table 3. Transient and Steady State Performance Indicators

\begin{tabular}{|c|c|c|c|c|c|c|c|c|c|c|c|}
\hline \multirow{2}{*}{$\begin{array}{l}\text { Pay } \\
\text { Load }\end{array}$} & \multirow{2}{*}{$\begin{array}{l}\text { Ref. } \\
\text { Pos. }\end{array}$} & \multicolumn{2}{|c|}{ Rise Time } & \multicolumn{2}{|c|}{ Overshoot } & \multicolumn{2}{|c|}{ Settling Time } & \multicolumn{2}{|c|}{$\begin{array}{l}\text { Steady State } \\
\text { Error }\end{array}$} & \multicolumn{2}{|c|}{$\begin{array}{c}\text { Integral of } \\
\text { Absolute Error }\end{array}$} \\
\hline & & FLC & SMC & FLC & SMC & FLC & SMC & FLC & SMC & FLC & SMC \\
\hline \multirow{6}{*}{0.1} & -30 & 0.03 & 0.02 & 0 & 9.03 & $\mathrm{NaN}$ & 2 & 1.62 & -1.26 & 5.65 & 3.68 \\
\hline & -20 & 0.06 & 0.02 & 6.18 & 12.44 & 0.22 & $\mathrm{NaN}$ & -0.54 & -1.99 & 4.28 & 4.55 \\
\hline & -10 & 0.02 & 0.01 & 57.93 & 23.48 & 0.26 & $\mathrm{NaN}$ & 0.38 & -2.91 & 1.69 & 6.46 \\
\hline & +10 & 0.02 & 0.01 & 54.61 & 58.73 & 0.21 & $\mathrm{NaN}$ & -0.15 & -0.85 & 1.32 & 4.32 \\
\hline & +20 & 0.06 & 0.01 & 6.68 & 22.21 & 0.24 & 2 & 0.58 & -1.34 & 4.74 & 3.44 \\
\hline & +30 & 0.09 & 0.01 & 0 & 14.75 & $\mathrm{NaN}$ & $\mathrm{NaN}$ & 1.66 & -2.41 & 5.82 & 5.11 \\
\hline \multirow{6}{*}{0.4} & -30 & 0.04 & 0.02 & 8.33 & 2.8 & $\mathrm{NaN}$ & 1.68 & -1.56 & -0.31 & 7.24 & 1.89 \\
\hline & -20 & 0.06 & 0.02 & 29.56 & 3.36 & 0.67 & 1.99 & 0.84 & -0.9 & 6.21 & 2.41 \\
\hline & -10 & 0.03 & 0.03 & 77.21 & 4.42 & $\mathrm{NaN}$ & $\mathrm{NaN}$ & 0.76 & -1.14 & 3.08 & 2.54 \\
\hline & +10 & 0.02 & 0.02 & 77.03 & 20.27 & $\mathrm{NaN}$ & $\mathrm{NaN}$ & -0.78 & -0.86 & 3.16 & 1.86 \\
\hline & +20 & 0.06 & 0.01 & 24.64 & 8.84 & 0.55 & $\mathrm{NaN}$ & -0.27 & -0.6 & 5.68 & 1.63 \\
\hline & +30 & 0.04 & 0.01 & 8.85 & 11.44 & 0.69 & 0.6 & 1.3 & -0.76 & 7.25 & 2.07 \\
\hline \multirow{6}{*}{0.7} & -30 & 0.04 & 0.02 & 19.76 & 1.83 & 0.95 & 0.06 & -1.41 & -0.33 & 7.78 & 1.69 \\
\hline & -20 & 0.06 & 0.02 & 39.97 & 2.83 & 0.92 & $\mathrm{NaN}$ & 0.75 & -0.66 & 7.1 & 1.94 \\
\hline & -10 & 0.03 & 0.02 & 64.29 & 0 & 0.53 & $\mathrm{NaN}$ & -0.16 & -0.8 & 2.75 & 1.86 \\
\hline & +10 & 0.03 & 0.04 & 61.53 & 13.41 & 0.53 & $\mathrm{NaN}$ & 0.37 & -0.39 & 3.1 & 1.09 \\
\hline & +20 & 0.06 & 0.02 & 41.06 & 5.59 & 0.91 & 1.79 & -0.5 & -0.53 & 7.16 & 1.41 \\
\hline & +30 & 0.04 & 0.04 & 19.78 & 19.78 & 0.96 & 0.96 & 1.13 & -0.38 & 7.58 & 1.56 \\
\hline \multirow{6}{*}{1.0} & -30 & 0.06 & 0.03 & 12.47 & 0.61 & 1.23 & 0.06 & -1.35 & -0.41 & 9.66 & 1.9 \\
\hline & -20 & 0.1 & 0.03 & 35.84 & 0.93 & 1.39 & 1.95 & 0.82 & -0.56 & 10.31 & 1.78 \\
\hline & -10 & 0.04 & 0.02 & 69.87 & 0.03 & 0.61 & $\mathrm{NaN}$ & -0.06 & -0.58 & 3.1 & 1.43 \\
\hline & +10 & 0.04 & 0.06 & 74.81 & 5.89 & 0.7 & 1.99 & -0.16 & $\begin{array}{l}-0.3 \\
\end{array}$ & 3.31 & 0.9 \\
\hline & +20 & 0.1 & 0.02 & 36.03 & 4.83 & 1.04 & 0.04 & -0.65 & -0.37 & 10.23 & 1.23 \\
\hline & +30 & 0.06 & 0.02 & 14.58 & 19.34 & 1.13 & 0.06 & 0.94 & -0.35 & 9.4 & 1.59 \\
\hline
\end{tabular}

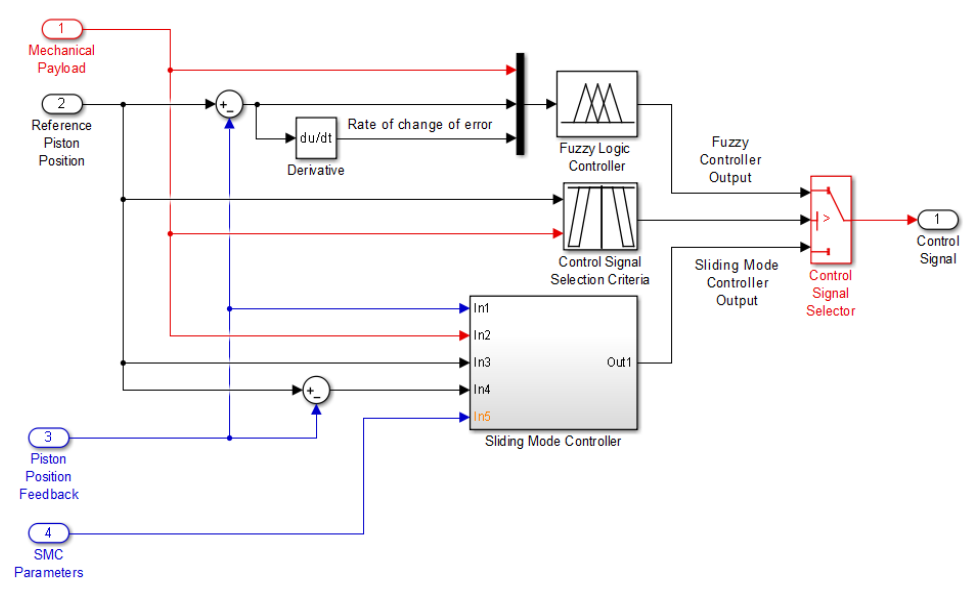

Figure 3. Exploded view of hybrid controller 


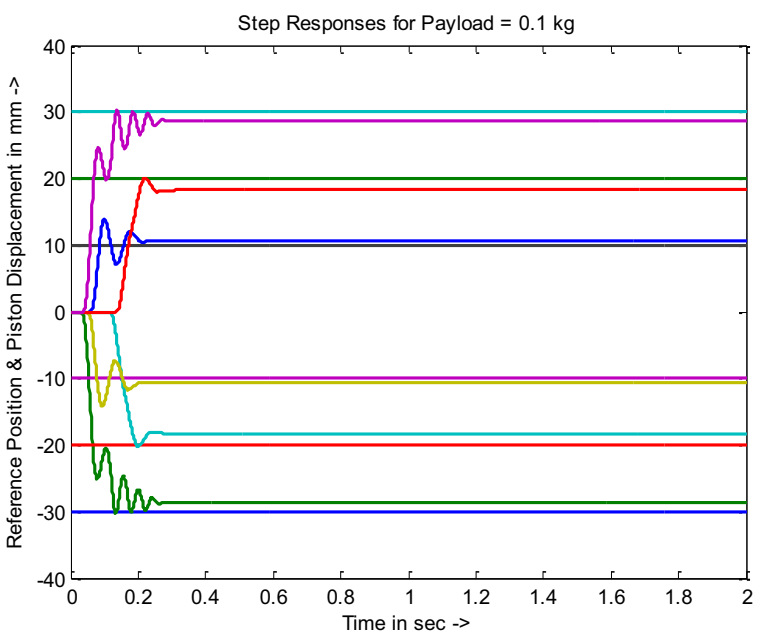

(a)

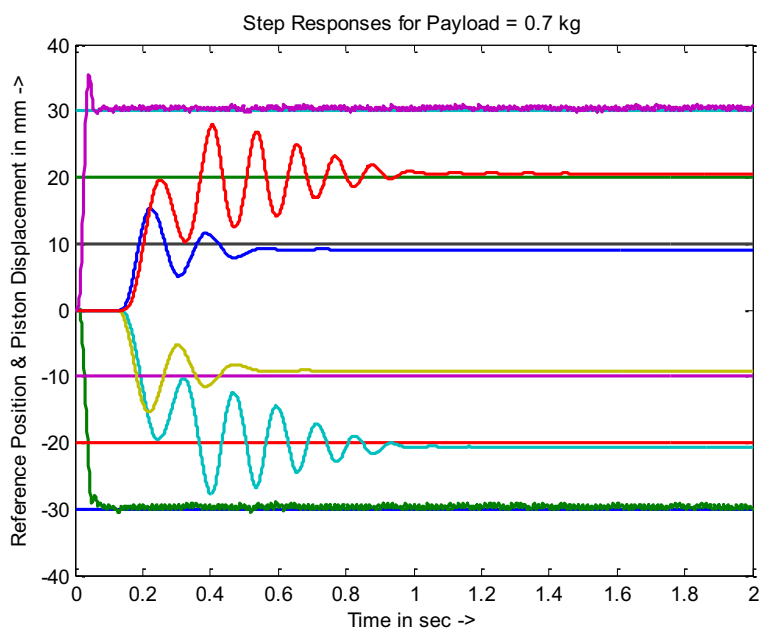

(c)

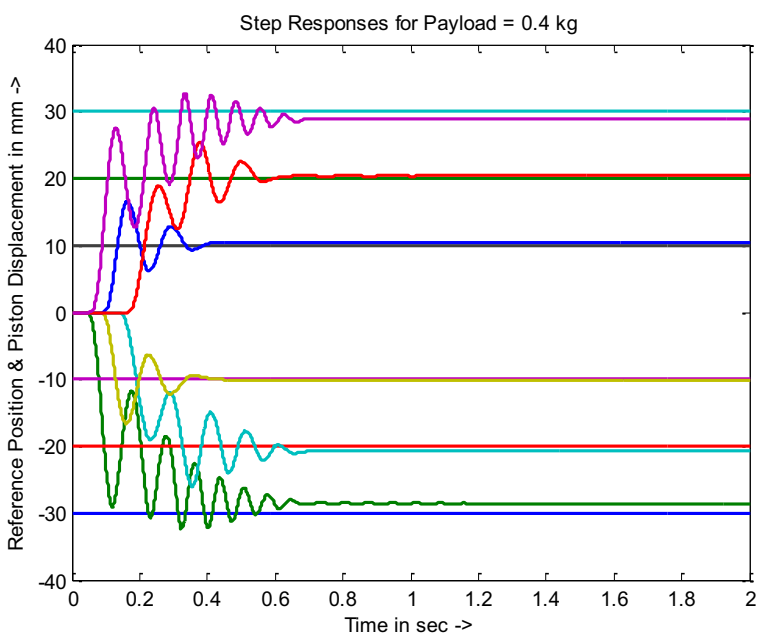

(b)

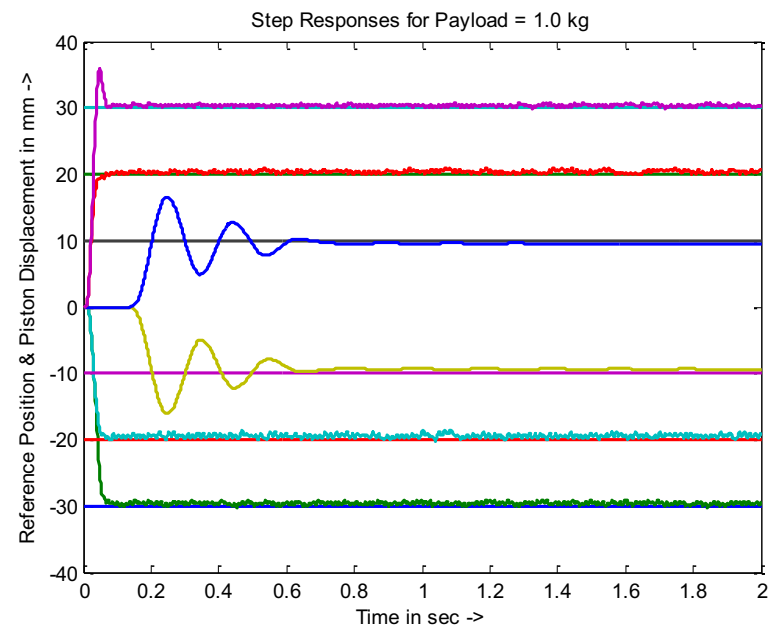

(d)

Figure 4. Positional response of pneumatic actuator with different payloads (a) $0.1 \mathrm{~kg}$ (b) $0.4 \mathrm{~kg}$ (c) $0.7 \mathrm{~kg}$ (d) $1.0 \mathrm{~kg}$

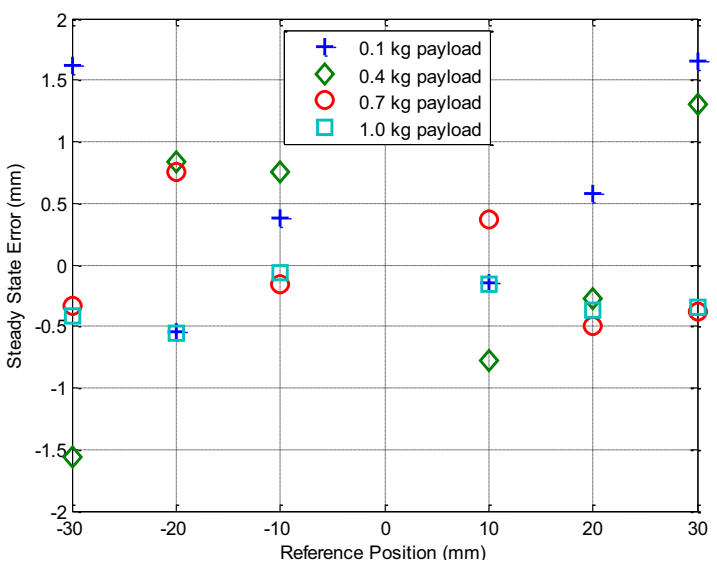

(a)

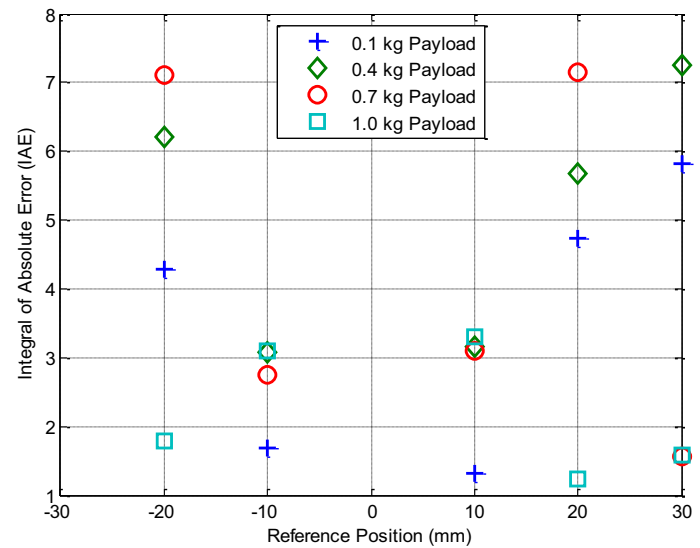

(b)

Figure 5. Piston Positional (a) steady state positional error and (b) Integral of Absolute Error with Hybrid Controller

Table 4. Control matrix for payload and piston displacement combinations

\begin{tabular}{|l|l|l|l|l|c|}
\hline $\begin{array}{l}\text { Ref. } \\
\text { Pos. } \\
(\mathrm{mm}) \downarrow\end{array}$ & $\begin{array}{l}\text { Pay } \\
\text { Load } \\
(\mathrm{kg}) \rightarrow\end{array}$ & 0.1 & 0.4 & 0.7 & 1.0 \\
\hline \multicolumn{2}{|l|}{-30} & FLC & FLC & SMC & SMC \\
\hline-20 & FLC & FLC & FLC & SMC \\
\hline-10 & FLC & FLC & FLC & FLC \\
\hline
\end{tabular}

\begin{tabular}{|l|l|l|l|l|c|}
\hline $\begin{array}{l}\text { Ref. } \\
\text { Pos. } \\
(\mathrm{mm}) \downarrow\end{array}$ & $\begin{array}{l}\text { Pay } \\
\text { Load } \\
(\mathrm{kg}) \rightarrow\end{array}$ & 0.1 & 0.4 & 0.7 & 1.0 \\
\hline \multicolumn{2}{|l|}{+10} & FLC & FLC & FLC & FLC \\
\hline+20 & FLC & FLC & FLC & SMC \\
\hline \multicolumn{2}{|l|}{} & FLC & FLC & SMC & SMC \\
\hline
\end{tabular}




\section{Conclusions}

A hybrid controller was synthesized using fuzzy logic control and sliding mode control for position control of a pneumatic actuation system. Simulation was employed for obtaining the transient and steady state response of the pneumatic actuator for various combinations of applied payloads and piston displacements. The quantitative results emphasized that hybrid FLC-SMC controller exhibited effective position control for pneumatic actuation system as fuzzy logic control was effective for combinations of lower payloads and smaller piston displacements, whereas sliding mode controller was effective for combinations of higher payloads and larger piston displacements.

\section{References}

1. T. Nguyen, J. Leavitt, F. Jabbari, J. E. Bobrow, IEEE/ASME Transactions on Mechatronics, 12 (2), pp. 216-219, (2007)

2. G. M. Bone, S. Ning, IEEE/ASME Transactions on Mechatronics, 12 (5), pp. 557-561, (2007)

3. M. Taghizadeh, F. Najafi, A. Ghaffari, International Journal of Advanced Manufacturing Technology, 48(5), pp. $655-662$, (2010)

4. M. Taleb, A. Levant, F. Plestan, Control Engineering Practice, 21(5), pp. $727-736$, (2013)

5. S. N. S. Salim, M. F. Rahmat, A. A. M. Faudzi, Z. H. Ismail, N. Sunar, Mathematical Problems in Engineering, http://dx.doi.org/10.1155/2014/957041, (2014)

6. Edmond Richer and Yildirim Hurmuzlu, ASME J. Dynamic Systems, Measurement and Control, 122, pp. 416-425, (2000)

7. S. S. Dhami, S. S. Bhasin, P. B. Mahapatra, ASME International Mechanical Engineering Congress and
Exposition, November 13-19, Lake Buena Vista, Florida, USA, (2009)

8. R. C. Dorf, R. H. Bishop, Modern Control Systems, Pearson Education, Delhi, India, (2005)

\section{Appendix}

$\mathrm{A}_{1}$ : Piston area on cap end side $\left(2.85 \times 10^{-4} \mathrm{~m} 2\right)$

$\mathrm{A}_{2}$ : Piston area on rod end side $\left(2.53 \times 10^{-4} \mathrm{~m} 2\right)$

$\mathrm{A}_{\mathrm{r}}$ : Piston rod area $\left(3.17 \times 10^{-5} \mathrm{~m} 2\right)$

$\mathrm{C}_{\mathrm{f}}$ : $\quad$ Valve orifice discharge coefficient $(0.25)$

$\mathrm{c}_{\mathrm{s}}$ : Viscous friction coefficient of control valve $(7.5 \mathrm{~N}-\mathrm{s} / \mathrm{m})$

D: Connecting tube diameter $(0.0032 \mathrm{~m})$

$\mathrm{F}_{\mathrm{df}}$ : Kinetic friction force for cylinder $(0.486 \mathrm{~N})$

$\mathrm{F}_{\mathrm{sf}}$ : Static friction force for cylinder $(3.8 \mathrm{~N})$

$\mathrm{K}_{\mathrm{fc}}$ : Valve coil force coefficient $(2.78 \mathrm{~N} / \mathrm{m})$

$\mathrm{k}_{\mathrm{s}}$ : Spring stiffness coefficient of control valve $(975 \mathrm{~N} / \mathrm{m})$

$\mathrm{k}_{\mathrm{se}}$ : Spring stiffness coefficient of load $(205 \mathrm{~N} / \mathrm{m})$

L: $\quad$ Total cylinder stroke $(0.0762 \mathrm{~m})$

$\mathrm{L}_{\mathrm{t}}$ : Length of connecting tube $(0.5 \mathrm{~m})$

$\mathrm{M}_{\mathrm{p}}$ : Piston and rod combined mass $(0.055 \mathrm{~kg})$

n: Polytropic constant (1.3)

$\mathrm{P}_{\mathrm{a}}$ : Atmospheric pressure $\left(101.3 \times 10^{3}\right.$ Pascal (absolute)

$\mathrm{P}_{\mathrm{s}}$ : Supply pressure $\left(506.5 \times 10^{3}\right.$ Pascal (absolute) $)$

$\mathrm{T}_{\mathrm{a}}$ : Air temperature $(293 \mathrm{~K})$

$\mathrm{V}_{01}$ : Dead volume of cap end side cylinder-chamber $\left(2.17 \times 10^{-6} \mathrm{~m}^{2}\right)$

$\mathrm{V}_{02}$ : Dead volume of rod end side cylinder-chamber $\left(1.93 \times 10^{-6} \mathrm{~m}^{2}\right)$

$\beta$ : $\quad$ Viscous friction coefficient for cylinder (4.47 N-s/m)

$x_{d}:$ Desired piston position

$\mathrm{x}$ : piston displacement measured from the mid-stroke 